\title{
Produzir e compartilhar: a produção de professores da educação \\ básica no YouTube
}

\section{Producing and sharing: the productions of basic education teachers on YouTube}

\section{Producir y compartir: la producción de profesores de la educacaión básica en YouTube}

\author{
Simone Lucena* \\ Gersivalda Mendonça da Mota** \\ Sandra Virginia Correia da Andrade Santos ${ }^{* *}$
}

\section{Resumo}

Este artigo é resultado de uma pesquisa que buscou compreender as possibilidades de utilização do YouTube na educação, envolvendo uma proposta de criação e cocriação de vídeos, junto aos professores da educação básica. A metodologia utilizada foi a pesquisa-formação, a qual requer do pesquisador uma implicação com os sujeitos e com os dispositivos da investigação. Nesse sentido, foi criado um dispositivo autoral de formação continuada docente, a oficina "Possibilidades do uso da rede social YouTube na educação". A pesquisa-formação tem como aporte teórico Josso (2010), Macedo (2009, 2010) e Santos (2014). Os dispositivos para levantamento de dados foram: observação, diálogo com os participantes e diários de campo. Como resultado, verificou-se que nem todos os professores se apropriaram da dinâmica de criação e/ou cocriação de vídeos, bem como do compartilhamento de suas produções. Alguns demonstraram insegurança e resistência. Dessa forma, concluímos que a ausência de práticas autorais e dinâmicas, por parte dos professores envolvidos, está relacionada principalmente a dois fatores: dificuldades de imersão na cibercultura e de disponibilidade para a realização de atividades de formação continuada, pois as políticas educacionais, seja no nível municipal, estadual ou federal, não têm possibilitado que os professores tenham disponibilidade para realizar sua formação continuada.

Palavras-chave: autoria; cibercultura; educação básica; formação docente; YouTube.

Recebido em: 30/07/2020 - Aprovado em: 06/04/2021

http://dx.doi.org/10.5335/rep.v28i1.11466

Doutora em Educação. Professora do Departamento de Educação e do Programa de Pós-graduação em Educação da Universidade Federal de Sergipe / Campus Universitário Prof. Alberto Carvalho. Líder do ECult - Grupo de Pesquisa em Educação e Culturas digitais. Orcid: http://orcid.org/0000-0003-1636-7707. E-mail: sissilucena@gmail.com

** Graduada em História pela Universidade Tiradentes. Mestre em Educação pela Universidade Federal de Sergipe. Orcid: https://orcid.org/0000-0002-7764-5144. E-mail: historiagerssyn@hotmail.com

*** Graduada em Letras e mestre em Língua Portuguesa pela Universidade Federal de Sergipe. Doutoranda em Educação pela Universidade Federal de Sergipe. Orcid: https://orcid.org/0000-0002-0129-056X. E-mail: sanlitera@yahoo.com.br 


\section{Abstract}

This paper is the result of a research that sought to understand the possibilities of using the YouTube social network in education, involving a proposal of creation and co-creation of videos, together with teachers of basic education. The methodology used was the research-training, which requires the researcher an implication with the subjects and the research devices. In this regard, an authorial device for teacher training was created, the workshop "Possibilities of using the YouTube social network in education". The research-training has as theoretical contribution Josso (2010), Macedo $(2009,2010)$ and Santos (2014). As data collection device, observation, dialogue with the participants, and field journal were used. As a result, it was verified that only one teacher had already appropriated the dynamics of creation and/or co-creation of videos, as well as the sharing of their productions. The other ones demonstrated insecurity and resistance. In this way, we conclude that the lack of construction of authorial practices and dynamics by the teachers involved is mainly related to two factors: difficulty in cyberculture immersion and availability for continuing education activities, since educational policies, whether at the municipal, state or federal levels, have not made it possible for teachers to be available to carry out their continuing education.

Keywords: authorship; cyberculture; basic education; teacher training; YouTube.

\section{Resumen}

Este artículo es el resultado de una investigación en la que se tuvo como reto comprender las posibilidades de utilización de la página web de red social YouTube en la educación, involucrando una propuesta de creación y creación conjunta de vídeos, junto a los profesores de la educación básica. Se utilizó la metodología investigación-formación, la cual requiere del investigador implicarse con los sujetos y con los dispositivos de la investigación. En este sentido, se creó un dispositivo de autoría propia de formación continua docente, el taller "Posibilidades del uso de la red social YouTube en la educación". La investigación-formación tiene como aporte teórico Josso (2010), Macedo $(2009,2010)$ y Santos (2014). Como dispositivo de búsqueda de datos se utilizó la observación, diálogo con los participantes, y diarios de campo. Como resultado, se verificó que no todos los profesores se apropiaron de la dinámica de creación y/o creación conjunta de vídeos, bien como no compartieron sus producciones. Algunos demostraron inseguridad y resistencia. De esta forma, concluimos que la falta de construcción de prácticas de autoría y dinámicas, de parte de los profesores involucrados, se relaciona principalmente a dos factores: dificultad de inmersión en la cibercultura y de la disponibilidad para la realización de actividades de formación continua, pues las políticas educacionales, tanto en nivel municipal como los niveles estadual o federal, no les posibilitan a los profesores que tengan disponibilidad para realizar su formación continua.

Palavras-clave: autoría; cibercultura; educación básica; formación docente; YouTube.

\section{Introdução}

$\mathrm{O}$ atual contexto sociotécnico tem possibilitado mudanças nas formas de agir, pensar e produzir informações no cotidiano dos praticantes culturais, os quais realizam, cada vez mais, diversas atividades com seus dispositivos móveis na palma da mão, especialmente, os smartphones e tablets. Nesse sentido, por meio da disseminação das tecnologias móveis digitais ou "tecnologias nômades" como denomina Silva (2013), passou-se a ter outras formas de se comunicar, de produzir e de se relacionar com pessoas de diferentes lugares, pois essas tecnologias potencialmente

"reinventam espaços urbanos como ambientes de multiusuários, significando que 
é possível se comunicar com indivíduos que não estão presentes fisicamente, ao mesmo tempo em que se move pelo espaço físico, que é também habitado por outras pessoas" (SILVA, 2013, p. 283).

Diante desse cenário social e tecnológico emergente, bem como das práticas desenvolvidas nos mais variados espaços, inclusive nos educativos, em que os recursos digitais estão cada vez mais presentes, essa pesquisa propõe compreender as possibilidades de utilização da rede social YouTube por professores da educação básica, com finalidades pedagógicas, uma vez que os vídeos criados e compartilhados nesta rede social fazem parte cotidianamente dos praticantes culturais em contextos diversos. Para chegar ao objetivo traçado, parte-se da concepção de um sujeito construtor de uma cultura, a qual é construída a partir do desenvolvimento de sua prática, de sua maneira de pensar e de agir no mundo. Trata-se, portanto, de uma pesquisa-formação, metodologia justificada pelo fato de situar-se numa perspectiva de compromisso e de implicação dos pesquisadores com suas práticas, permitindo mudanças individuais e/ou coletivas.

Desse modo, ao fundamentar-se no contexto da pesquisa-formação de Macedo (2009, 2010) e Josso (2010), esta pesquisa consubstancia-se nas contribuições dos autores citados para a formação do professor-pesquisador de modo a não gerar um engessamento das rígidas posições teóricas e encaminhamentos metodológicos que destituem a condição de praticante diante da ação em que se encontra imerso. Sendo assim, o pesquisador se encontra inserido em toda a pesquisa como sujeito, a fim de que ele também venha a desfrutar da experiência de toda a atividade desenvolvida, constituindo-se como um indivíduo aprendente.

Na mesma perspectiva, têm-se as ideias de Macedo (2009), o qual afirma que esse tipo de pesquisa valoriza as práticas, o saber-fazer plural, produzido pelos sujeitos autorais e permite sair do instituído para achar o imprevisto, a ousadia produzida pelo sujeito praticante. Ao ir a campo para fazer as observações, o pesquisador deve se despir dos seus próprios conceitos e estar aberto ao que está posto por meio das práticas cotidianas dos professores e da realidade. Portanto, os sujeitos de uma pesquisa-formação são ativos em todo o processo de formação, pois desenvolvem uma cultura por meio de seus atos sociais, são instituídos da ordem sociocultural e são construtores ativos, direcionados a outras possibilidades (MACEDO, 2009). Ainda de acordo com este autor, os sujeitos são peças importantíssimas para caracterizar a pesquisa, sendo cada fala de extrema importância, pois produzem sentidos e significados. Sem o sujeito, sem a sua voz, seria impossível desenvolver uma pesquisa-formação. 
Nesse sentido, esta investigação apresentou-se como uma caminhada em conjunto com outros em busca do ponto de vista do outro para interpretar suas realizações. Macedo (2010) defende que as formas de construção do conhecimento originadas da vida do cotidiano escolar são significativas para pensar, dado o conjunto de interpretações que as pessoas compartilham e que, ao mesmo tempo, fornecem os meios e as condições para que essas interpretações aconteçam.

Macedo (2010) enfatiza ainda que, nesse tipo de pesquisa, os atores socais instituintes da ordem sociocultural a ser compreendida não falam pela boca da teoria ou de uma estrutura fatalística; suas ações e suas racionalidades são percebidas como estruturantes, em meio às estruturas socioculturais que, em muitos momentos, recursivamente, os configuram. Desse modo, o pesquisador é ativo em todo o processo, sendo objeto e sujeito da pesquisa. Assim, ao mesmo tempo, reflete a própria prática e aprende, conforme desenvolve a pesquisa. Ou seja, aprende enquanto pesquisa e pesquisa enquanto aprende. Esse movimento é muito importante para que o professor tenha contato com outras práticas e experiências, as quais podem servir de ensinamentos para que, posteriormente, ele venha a atuar de maneira a seguir, ou não, os exemplos vivenciados. Trata-se de um momento de aprendizagem e reflexão de suas ações e práticas (MACEDO, 2010).

Portanto, pretendeu-se trilhar uma pesquisa embasada nos fundamentos de "um rigor outro" que consiste em problematizar, questionando as formas de pensamentos constituídas e normatizadas. Para Macedo (2009), fazer pesquisa com "um rigor outro" coloca o pesquisador na formação experienciada, numa mútua relação entre os saberes científicos, as práticas e seus entretecimentos ou hibridismo, mediante o cultivo de uma epistemologia plural, crítica e emancipacionista, dando ênfase aos saberes outros: os saberes não acadêmicos, as experiências e o cotidiano. Outrossim, essa forma de fazer pesquisa permite a construção de dispositivo ou dispositivos para serem desenvolvidos junto aos sujeitos da investigação. Por dispositivo, Ardoino (2003, p. 80) define "uma organização de meios materiais e/ou intelectuais, fazendo parte de uma estratégia de conhecimento de um objeto". Ou seja, entendemos que dispositivo é tudo aquilo que produzimos, criamos ou cocriamos para melhor conhecer e interagir com os sujeitos e objetos da pesquisa. Sendo assim, a experiência dos atores sociais possui legitimidade própria, pois as pessoas produzem suas ordens sociais, de onde brotam saberes e experiências. Desse modo, é no campo, e a partir dele, que toda a pesquisa toma forma, tudo é desenvolvido pensando na realidade posta e não na já instituída previamente, pois parte do contexto real e das suas necessidades. 
Para Macedo (2010), o método requer grande dispêndio de tempo para o pesquisador aproximar-se daqueles para os quais ele pode não ser familiar. Porém, nesse tipo de pesquisa, é o objeto de estudo que vai fornecer uma decisão quanto à quantidade de tempo e à dimensão do período de observação, além do grau de envolvimento necessário. Partindo desse pressuposto, portanto, urge a necessidade de uma formação adequada e continuada para que os professores possam adquirir competências que lhes permitam fazer uso das TDIC em sala de aula, numa perspectiva de construção do conhecimento. A partir dessa constatação, propôs-se um dispositivo formativo, na perspectiva de oficina, intitulado "Possibilidades do uso da rede social YouTube na educação", a fim de conhecer como os professores fazem uso do YouTube, bem como lhes apresentar outras potencialidades do site de rede social, como, por exemplo, a criação de um canal próprio para armazenar os vídeos favoritos, bem como a criação, cocriação e socialização de suas produções.

O olhar cuidadoso é uma das principais características desse tipo de pesquisa, pois, conforme afirma Macedo (2010), é necessário um esforço incessante para analisar a realidade como está sendo apresentada, com todas as impurezas, de modo que a pesquisa não consista em apenas observar e registrar fatos. Sobre esse assunto, Santos (2014) descreve que a pesquisa-formação na contemporaneidade se atenta para a relação entre história de vida, formação inicial e continuada, tal como a aprendizagem construída ao longo da carreira e do exercício da sua profissão, onde o docente interage e aprende com estudantes e pares. Contudo, cabe ressaltar que não foi sempre assim, pois até metade do século XX a ênfase era para a formação inicial direcionada apenas para a aprendizagem. Portanto, conforme afirma Santos (2011), para que a diversidade de linguagens, produções e experiências de vida sejam contempladas nos e pelos espaços de aprendizagem, os saberes precisam ganhar visibilidade e mobilidade coletiva, ou seja, os sujeitos do conhecimento precisam reconhecer a sua alteridade, sentindo-se envolvidos em uma produção coletiva, dinâmica e interativa, rompendo com o espaço tempo. Eles precisam entender e conhecer a importância de suas produções.

Desse modo, precisa-se dar ênfase à formação atual, pensando nas possibilidades e transformações sociais, não somente ao que está posto. Ribeiro (2015) afirma que pensar a formação docente no contexto atual nos remete, de alguma forma, às grandes transformações sociais em todos os setores da contemporaneidade, em função das práticas interativas e da consequente cultura participativa que se prolifera em função das tecnologias digitais e do advento da hipermobilidade e da ubiquidade possibilitadas pelos dispositivos móveis. Tudo isso foi levado em 
consideração ao se construir a proposta da oficina "Possibilidades de uso da rede social YouTube na educação" como dispositivo formativo e de pesquisa.

\section{Materiais e métodos}

Na contemporaneidade, ao se estar imerso em uma nova cultura, ou melhor, na cibercultura, entende-se que as pessoas estão cada vez mais conectadas em rede e gastam parte do seu tempo em ambientes plurais e virtuais. Assim, uma vez que as pessoas estão cotidianamente inseridas nesses ambientes e, em contato constante com todo tipo de conteúdo de que precisam para as mais variadas práticas sociais, questiona-se como os professores podem utilizar-se de tais dispositivos de maneira a contribuir para o desenvolvimento de suas aulas e, consequentemente, para uma melhor aprendizagem de seus alunos.

Partindo desse questionamento e entendendo que o site de rede social YouTube dispõe de possibilidades para criar e cocriar materiais audiovisuais por meio de adequação, reaproveitamento, edição e reedição, propiciando a apresentação de uma série de conteúdos de qualidade, essa investigação buscou compreender e apresentar as possibilidades do site de rede social Youtube para a educação básica. Desta forma, têm-se como questões norteadoras da pesquisa como os professores fazem uso da rede social YouTube e quais suas possibilidades de utilização, de modo a potencializar práticas autorais a partir do que a própria rede social disponibiliza.

Para o levantamento das informações iniciais, as quais seriam fundamentais para o desenvolvimento desta proposta, fora feita uma conversa no campo da pesquisa com os possíveis participantes e, após este diálogo, os mesmos responderam a um formulário on-line para composição de outros dados importantes para o processo investigativo. Essa conversa ocorreu de forma individual no próprio ambiente escolar, durante os intervalos e horários vagos, tanto na sala dos professores, quanto nos corredores e espaços coletivos. Durante as observações na escola, desenvolveu-se maior aproximação com os professores no intuito de conhecê-los e promover maior aceitação da pesquisadora no cotidiano escolar. Nesse sentido, durante os intervalos entre as aulas, era comum conversar sobre variados assuntos educativos, tais como: cumprimento de calendário escolar, planejamento das aulas, semana de avaliação, conteúdos, dificuldades enfrentadas pelos docentes, recursos tecnológicos oferecidos pela escola e suas funcionalidades, entre outros.

Assim, foi necessário imergir no campo de pesquisa durante dias e horas, pois enquanto estavam na escola, os professores tinham horários a serem cumpridos e, 
por isso, nem sempre podiam dar total atenção ou dispor de horas para conversar sobre a pesquisa. Essa imersão no próprio campo da pesquisa, especificamente no momento dos intervalos na sala dos professores, fora de fundamental importância para ganhar a confiança dos professores, pois, estando entre eles, foi possível perceber que pareciam mais à vontade para demonstrar seus sentimentos sobre a escola, a educação e sobre os recursos que já faziam uso nas suas práticas de sala de aula. Outrossim, ressalta-se que esse contato inicial da pesquisa, além de promover a aproximação entre pesquisador e participantes, foi pensado com dois intuitos: apresentar a pesquisa, seus objetivos e sua relevância; e identificar os usos que os próprios professores já faziam da rede social YouTube.

Durante este período de contato direto no locus escolhido para a pesquisa, o Colégio Estadual Professor Nestor Carvalho Lima, localizado na cidade de Itabaiana, SE, os professores demonstraram interesse em participar e colaborar, no entanto faltava a disponibilidade de tempo para fazer parte da Oficina. Essa impossibilidade poderia comprometer o desenvolvimento da proposta, contudo, uma das professoras demonstrou maior disponibilidade para participar e informou que, por estar atuando como supervisora do Programa Institucional de Bolsa de Iniciação à Docência (Pibid) do curso de Pedagogia da Universidade Federal de Sergipe, Campus Prof. Alberto de Carvalho, em Itabaiana, SE, poderia participar da formação e, inclusive, convidaria os demais professores. Assim, por intermédio dessa professora participante, foram convidados os professores do Pibid para participarem da oficina sobre YouTube na educação, delineando novos espaços e participantes. Desse modo, consolidaram-se como sujeitos da pesquisa duas professoras do Colégio Estadual Nestor Carvalho Lima, no município de Itabaiana, e três professores das escolas municipais da mesma cidade, os quais faziam parte do Pibid no período de 2014 a 2018.

Por se tratar de uma pesquisa que tem como foco a formação docente, decidiu-se então utilizar como metodologia para sua realização a pesquisa-formação, pois possibilita contemplar e atender às perguntas da pesquisa e aos objetivos elencados. Essa escolha se dá por esta metodologia levar em consideração o sujeito e a sua formação, seja ela inicial ou continuada, considerando o seu cotidiano e a sua prática, as vivências e experiências que contribuem para sua própria formação. Para tal, fora desenvolvido um dispositivo autoral, uma oficina de quarenta horas, realizada no laboratório de informática da Universidade Federal de Sergipe, Campus Alberto Carvalho, onde foi possível compartilhar conhecimentos sobre os usos já presentes nas práticas dos professores, bem como possibilidades outras 
de utilização do site de rede social YouTube na educação, como, por exemplo, o desenvolvimento de um canal no próprio YouTube, em que o professor passaria a produzir e postar os seus próprios vídeos, podendo compartilhar esses materiais com os alunos e demais professores.

\section{Análises e resultados}

Esta pesquisa tratou-se de uma imersão no contexto das práticas escolares, tentando identificar o uso da rede social YouTube pelos professores, bem como dissolver com os próprios professores outras possibilidades de uso pedagógico. Durante o processo, foi necessário inserir-se no ambiente da escola com olhar plural acerca do processo formativo, sendo sujeito e autor praticante da pesquisa, inserindo-se nas reflexões.

Em meio às primeiras observações no campo, identificou-se que, das cinco professoras, duas já utilizavam o site de rede social YouTube para fazer suas pesquisas em casa, baixar o arquivo e apresentar o conteúdo via televisão na sala de aula. A escola dispunha de internet, entretanto, nem todos os dias funcionava adequadamente. Assim, optava-se por baixar em casa no pendrive para expor o vídeo no televisor da escola, evitando, assim, contratempos. Os professores relataram também que, apesar de possuir laboratório de informática e rede Wi-Fi, essa rede não possuía velocidade adequada para atender a toda a comunidade escolar. Outro aspecto relacionado às tecnologias era o fato de a escola não possuir funcionários para solucionar os problemas existentes. Desta forma, quando havia algum problema nos equipamentos, era necessário solicitar agendamento com o técnico à Diretoria Regional de Educação do município (DRE-03), um processo demorado, pois, segundo a professora da escola, só havia um técnico para atender todas as escolas da DRE-03, a qual administra 15 escolas.

Após o levantamento da realidade escolar, ficou constatado que a escola não possuía as condições de infraestrutura tecnológica adequadas para a realização do curso para formação de professores. Por esta razão o curso foi realizado nas dependências da Universidade Federal de Sergipe - Campus Professor Alberto Carvalho.

Como afirmado por Macedo (2010), a pesquisa se desenvolve dentro do campo e não fora, pois, para compreender as perspectivas dos entrevistados, é necessário um mergulho com todos os sentidos para perceber detalhes sutis aparentemente imperceptíveis. Alguns professores ao iniciar o curso apontaram que já conheciam o site de rede social YouTube e que consideravam os muitos vídeos interessantes, 
com assuntos variados e aos quais costumavam utilizar, mas não em sala de aula. A professora B afirmou que:

Inúmeras vezes uso o YouTube para pesquisar conteúdos escolares, receitas de bolo e de sobremesas, como fazer tarefas e usar determinados equipamentos, aqui também buscamos receitas caseiras para qualquer problema de saúde, é fantástico a utilidade e variedade de coisas que encontramos aqui (PROFESSORA B).

Nesse processo de diálogo, os docentes também ressaltaram a necessidade de saber escolher o vídeo, bem como a necessidade de orientar os alunos a fazer escolhas quanto ao uso desses em suas pesquisas diárias. Além disso, no que diz respeito à importância do uso das TDIC na educação, a professora B entende que o uso delas é de fundamental importância para incentivar a participação dos alunos e inseri-los no contexto de construção da aprendizagem. Ressalta ainda que esses alunos já estão inseridos no contexto cibercultural e são imersivos no que diz respeito às redes sociais. Para ela, é perceptível que eles usam o tempo todo: "Se pudéssemos desenvolver projetos escolares em que articulássemos os conteúdos pedagógicos às TDIC, sei que teríamos bons resultados e aceitação da maioria dos alunos", afirma.

Questionamos sobre o motivo que impede os professores e a escola de articularem projetos pedagógicos associados ao uso das TDIC, obteve-se o seguinte relato da professora $\mathrm{C}$ :

Seria necessário que os professores tivessem uma formação para que eles pudessem melhor desenvolver ideias e executá-las, a fim de trazer melhores resultados, muitas vezes a falta de familiaridade sobre o uso e o desconhecimento das possibilidades de uso para a educação inibe a aplicabilidade em sala de aula, acredito que o professor não se sente entusiasmado em utilizar algo que ele não tenha segurança (PROFESSORA C).

Durante o período de observação, ficou evidente que os professores participavam de redes sociais de forma imersiva no seu cotidiano social; entretanto, não possuíam conhecimento mais aprofundado sobre suas possibilidades para a educação. A professora $\mathrm{C}$ afirma que:

O uso da rede social, das TDIC, faz parte da nossa cultura e muito mais da cultura dos nossos alunos. Eles gastam parte do seu tempo com elas, assim como nós. Se desenvolvêssemos algo para atraí-los, tornando-os ativos em todo processo, sem dúvida, teríamos bastante aceitação.

Nesse momento, detectou-se que os professores da escola utilizavam o site do YouTube para atualizar seu conhecimento acerca dos conteúdos a serem ministrados em suas aulas, ou seja, eles o utilizavam como ferramenta de pesquisa. 
Além do site YouTube, também faziam uso de outros recursos como livros didáticos, revistas, entrevistas e jornais para ampliar seu repertório. Com a aplicação do formulário on-line, a fim de obter novas informações sobre o uso que estes faziam do YouTube em suas práticas, os cinco professores reafirmaram utilizar a rede social para pesquisa, muitas vezes levando os vídeos para aplicação em suas aulas, considerando-os como um importante e atrativo recurso pedagógico e promotor de maior possibilidade de fixação dos conteúdos.

Em contrapartida, essa realidade das práticas educativas sinaliza a presença recorrente de um uso passivo, já que o que mais há é a pesquisa sobre determinados conteúdos, os quais serão repassados transmissivamente aos alunos. Nesse sentido, embora considerem importante tanto para pesquisa pessoal quanto para suas aulas, com possibilidades de colaborar na aprendizagem, ampliar e fixar conhecimentos por meio dos conteúdos variados e disponíveis, há uma limitação significativa neste uso. Nas relações de sala de aula com os alunos, por exemplo, professores reconhecem que os alunos são conquistados por aulas e atividades diferenciadas, inclusive com uso de vídeo e celulares, entretanto, poucos professores se utilizavam dos recursos disponíveis.

Nessa pesquisa, portanto, especificamente por meio do formulário on-line aplicado aos professores envolvidos, percebeu-se que as práticas realizadas pelos professores, diante das possibilidades oferecidas pelo YouTube, ainda eram muito restritas, não se apropriando das suas potencialidades, principalmente como forma de apresentar novas linguagens, autoria própria e formatos diferenciados. $\mathrm{Na}$ prática, restringe-se à busca pela fixação de conteúdos e/ou a ampliação do conhecimento dos próprios professores para, ao final, passar para seus alunos.

Partindo desta análise, percebe-se que os professores desconhecem outras possibilidades oferecidas pela rede social YouTube e, inclusive, não há uma apropriação ampliada. Cada professor se utiliza de uma forma, enquanto alguns já conseguem baixar para, posteriormente utilizar, outros nem essa habilidade mínima possuíam. Esses dados foram importantes para repensar as atividades de pesquisa a partir das informações obtidas pelos instrumentos de coleta, os quais deixam claro que os professores desconhecem que no site de rede social YouTube eles também podem produzir, compartilhar e ser autores, não se identificando como a(u)tores, os quais, de acordo com Lucena e Pretto (2009), são pessoas que, ao mesmo tempo, produzem conteúdos e também atuam em redes.

Essa realidade se dá principalmente pela falta de formação continuada dos professores da educação básica que promova habilidades docentes diante dos dis- 
positivos tecnológicos digitais. Diante desse fato, comprovou-se a necessidade de desenvolver uma oficina para mostrar aos professores possibilidades outras, dentre elas a de autoria de vídeos do YouTube e de postagens e reflexões por meio dos comentários que podiam ser feitos pelos alunos. Essa apropriação fora buscada a partir da oficina "Possibilidades do site de rede social YouTube na Educação", com carga horária de 40 horas, cuja proposta buscava, dentre outras possibilidades, incentivar os professores a se verem como autores, criando, cocriando e publicando seus conteúdos na rede. Esse processo formativo não seria responsável apenas pela produção dos dados da investigação, mas pela constituição de um espaço de formação em que os docentes desenvolvem competências necessárias e adequadas para utilizar as tecnologias digitais em sua prática pedagógica. Assim, para Santos (2014), a prática de formação é um lugar legítimo de formação e de aprendizagem significativa, não só referente ao pesquisador, como também a todos os participantes envolvidos nesse processo.

Ao perceber que o YouTube não era uma novidade para os professores, constatou-se a hipótese inicial de que a rede social que possibilita a criação e o compartilhamento de materiais audiovisuais já faziam parte do cotidiano dos professores, embora a maioria apenas consumia os materiais, o que demarca o desconhecimento das possibilidades plurais do site, já que não se viam como autores e coautores, apenas apreciadores de vídeos. Provavelmente, o uso passivo desses recursos audiovisuais na era digital se dá pela dificuldade de manusear o próprio computador, pois não sabiam postar, compartilhar, criar e alterar um perfil ou editar um vídeo produzido. Esse não domínio gera uma resistência, contribuindo cada vez mais para a passividade diante dos recursos tecnológicos.

Partindo dessa premissa, é importante destacar que o desenvolvimento do professor autor/criador e cocriador se constrói por meio de experiências no contexto escolar, nos espaços de formação, nas suas decisões de escolhas ao fazer um planejamento e definir tarefas e na sua prática diária. Isso se dá por meio de reflexão dos seus saberes, sejam eles existentes ou construídos. Porém, se não há processos formativos contínuos não há como os docentes se apropriarem dos dispositivos digitais que a cada dia se renovam e inovam suas possibilidades. Portanto, para Veloso (2014), a criação autoral pode ser identificada nas salas de estudos, onde os professores se debruçam para repensar e inovar a sua prática, como também nos espaços coletivos, ambientes físicos ou virtuais. Ele também identifica, em sua tese de doutorado, que durante o processo de autoria/criação os professores que usam a internet e os sites de rede social já possuem ações planejadas e que, no decorrer 
da pesquisa, recebem ajustes e com isso cocriam e criam etnométodos e táticas próprias, descobrem saídas e experimentam soluções. Eles fazem levantamento prévio, estabelecem provocações aos alunos, seguem a programação dos conteúdos e tentam atrelar o conteúdo à ação. Dessa forma, o processo de autoria/criação é inacabado, imprevisível, mutável, pois podem emergir novas práticas que podem potencializar outras criações. No entanto, em meio a essa perspectiva, percebe-se que os professores apresentam bastante ansiedade, provocada pelo desejo de produzir e, ao mesmo tempo, por depararem-se com a não compreensão das possibilidades e as dificuldades no momento da produção. Um exemplo disso se reflete na fala da professora B:

Acho as possibilidades de autoria interessantes, mas não tenho muita paciência de ficar 'futucando', ainda mais quando estou pesquisando e a busca está muito lenta, eu saio e deixo lá, minha filha é que faz algumas coisas para mim quando preciso.

Dos cinco professores participantes da pesquisa, quatro possuíam um nível de conhecimento básico com relação às interfaces virtuais; eles sabiam pesquisar, porém não sabiam de outras possibilidades para poder realizar as atividades propostas na oficina. Uma das professoras dessa pesquisa, a professora A, é imersa na cibercultura, habita as redes sociais. Ela possui blog, Facebook e canal no YouTube. Os demais possuíam canal, mas não eram imersos, habitavam raramente esse espaço, não produziam, compartilhavam ou postavam e somente uma delas costumava comentar as publicações.

Diante dessa realidade, é importante destacar que, além da importância e da necessidade da formação continuada para aperfeiçoamento dos profissionais da educação, devemos atentar para a questão da usabilidade e da interface humano-computador, compreendendo os diferentes graus de dificuldade para pessoas com mais ou menos habilidades e competências para o manuseio. Assim, devemos atentar a todo o contexto referente às dificuldades apresentadas pelos professores e compreender que existem algumas competências necessárias para uma utilização efetiva e que a formação continuada pode ser muito útil para aperfeiçoar a prática com o uso das tecnologias. Como ficou evidente, no percurso da pesquisa, os professores reconhecem a importância das TDIC, mas se paralisam diante da primeira dificuldade encontrada quando acessam ou precisam realizar algo na internet, não insistindo, diante do primeiro problema que surge. Esse fato deixa clara a necessidade de se garantir o empoderamento docente ao fazer uso dos dispositivos tecnológicos contemporâneos, e isso só será possível com um percurso formativo contínuo e permanente. 
A professora A já se apropriou disso. Produz vídeos ao fazer visitas a pontos específicos da cidade, tais como a feira de Itabaiana, o museu, os bairros próximos à escola, em visitas referentes ao projeto pedagógico "Cidade Espaço de Aprendizagem”. Ela criou, cocriou e divulgou seu trabalho em outras redes, como Facebook e seu próprio blog pessoal. Parte dos seus projetos escolares já eram postados em seu blog. Assim, a professora produz vídeos e posta também em seu próprio canal do YouTube, incorporando em seus vídeos várias linguagens, como sons, imagens, escrita, hiperlinks, possibilitando o desenvolvimento de vídeos mais atrativos.

Algo também debatido pelos próprios professores participantes foi a importância de saber selecionar conteúdos no YouTube, uma vez que nele se encontram os mais variados tipos de vídeos, do mais amador ao mais bem produzido. A sugestão apresentada foi procurar vídeos de pessoas que já possuem uma carreira estabilizada em ramos específicos, a exemplo os autores de livros que produzem suas palestras e reproduzem explicações de suas obras já renomadas no mercado e que possuem públicos específicos. A professora B ressalta que:

É preciso ter cuidados específicos com o conteúdo que foi selecionado para a sua pesquisa. Ao fazer uma pesquisa sobre o tema Independência Norte Americana, me deparei com vários vídeos e, ao visualizá-los, percebi que foram feitos por uma aluna do nono ano.

Não desmerecendo o conteúdo, mas a professora afirmou que esse vídeo, por não ter sido produzido por uma pessoa licenciada na área ou especialista, pode possuir informações desconexas. Além disso, as professoras destacaram a importância de verificar os comentários dos vídeos postados, pois através deles é possível avaliar o conteúdo e iniciar novas discussões, uma vez que cada comentário postado apresenta um perfil de discussão e viés variado de reflexão sobre aquele assunto, em graus diversos de complexidade. Além dessas percepções significativas sobre o YouTube, os professores também reconheceram a possibilidade de bloquear determinados comentários indevidos e/ou excluí-los, ampliando as possibilidades de uso.

Outra possibilidade reconhecida no percurso formativo foi a reedição dos vídeos. Permite-se fazer adaptações, reduzir, retirar cenas específicas, ou ampliar, incluindo outras, reeditando o conteúdo desejado como, por exemplo, adaptando para a idade específica, o que se configura uma cocriação. O professor, ao fazer esse processo, está fazendo uma nova produção com autoria própria e essa pode ser uma boa possibilidade para quem trabalha com educação básica, que exige cuidado com a faixa etária dos vídeos exibidos. Um exemplo de cocriação pode ser dado a partir 
do que fez a professora $\mathrm{A}$, que desenvolveu vídeos incorporando conteúdos variados e fazendo a reedição de conteúdo, adaptando para a idade específica. Dessa forma, ela fez o diferencial em suas atividades e projetos, adaptando com criatividade.

Outrossim, após todo percurso de compreensão das práticas de criação, recriação, cocriação, adentrou-se na possibilidade de postagem. Para isso, o professor pôde selecionar o tipo da postagem que queria fazer, escolhendo entre compartilhar de três formas: a) para o público, quando todos podem visualizar a postagem; b) privado, quando apenas quem foi selecionado poderá visualizar; c) formato não listado, no qual só é possível a visualização pelas pessoas que receberam seu link. Nessa perspectiva, a professora $\mathrm{C}$ considerou o formato de publicação para o público o mais interessante: "Nesse tipo de postagem, todas as pessoas podem visualizar, curtir, comentar e promover uma maior reflexão do conteúdo. Quanto maior o número de visualizações, maior será a possibilidade de ampliar as discussões sobre determinados conteúdos". Ainda sobre a postagem, a professora A compartilha uma forma de divulgar e expandir os conteúdos: "Uma maneira de fazer o seu canal ter bastante visualizações é compartilhar o link da postagem em, no mínimo, três outras redes sociais da internet para fazer circular e ganhar maior visibilidade, curtidas e compartilhamento". Ela já desenvolve esse recurso, ao postar o mesmo conteúdo em seu Blog, no Facebook e agora no YouTube, amplia o alcance das suas produções e oportuniza a utilização por outros sujeitos.

Destarte, a realização da oficina possibilitou discussões teóricas sobre a pesquisa-formação e a educação, apresentando as possibilidades de uso do site de rede social YouTube e também o compartilhamento de experiências sobre a efetivação da mesma no espaço escolar. Momentos como esse são de fundamental importância para os professores da rede pública de ensino, pois juntos há uma efetiva troca de experiências e socialização das várias possibilidades de uso a partir de experiências concretas, criando redes de aprendizagem coletiva.

\section{Discussões e conclusões}

Por meio do ciberespaço, podemos realizar vários procedimentos sem a necessidade de deslocamentos físicos, tais como o pagamento de contas, a emissão de extratos e declarações, compras em lojas de qualquer lugar do mundo, entre outras atividades. Diante da amplitude destas formas de cibercultura, não estar inserido nessa realidade é simplesmente fazer parte de um mundo desconectado e sem redes on-line. 
Neste contexto, os espaços educativos, também envolvidos com a cibercultura, passam a incorporar novas práticas, não apenas como fator motivacional, mas especialmente para apropriação dos professores, os quais já fazem uso tanto nas suas relações sociais quanto educacionais. Nessa perspectiva, tem-se o site de rede social YouTube, a partir do qual há a possibilidade de criação e cocriação, fato esse que contribui para o surgimento de autores de conhecimento, ou seja, pessoas que produzem com o propósito de construir novas aprendizagens e não apenas absorver informações, constituindo-se uma relação ativa dos sujeitos envolvidos em processos de produção, recriação e compartilhamento por meio das comunidades virtuais.

Nessa perspectiva, as possibilidades oferecidas com as tecnologias digitais são compreendidas como espaços multifacetados, com várias possibilidades de comunicação, interação, troca, produção e aprendizagem por meio de um universo de possibilidades que podem ser utilizadas a qualquer hora e em qualquer lugar, bastando apenas estar conectado (SANTAELLA, 2013). Sendo assim, no percurso da pesquisa, foram apresentadas várias possibilidades oferecidas pelo site de rede social YouTube, cabe então questionar: Qual é a maior dificuldade encontrada pelos professores? Por que eles (a maioria) não usam possibilidades múltiplas, limitando-se apenas ao uso passivo de algo pronto?

Para responder a estes questionamentos, não se pode pensar em inserir os novos recursos da comunicação na educação sem que seja garantida a qualidade do processo. Não se pode ter a ideia pura e simples de que esta ação promove uma nova educação e uma nova escola para o presente e futuro. Partindo dessa premissa, precisa-se, de fato, de uma integração mais efetiva entre a educação e a comunicação, o que só se dará se estes novos meios estiverem presentes nas práticas educacionais. A relevância de se desenvolver o ensino na rede social da internet se dá, principalmente, por sua capacidade de romper barreiras, reafirmando a aprendizagem que pode ocorrer em lugar e em espaços variados e em todo tempo, não exclusivamente em sala de aula. No entanto, para que isso seja possível, mais uma vez enfatiza-se a necessidade de uma formação continuada para os professores.

O professor do mundo contemporâneo deve assumir o ensino com o papel de mediador, adotando práticas interdisciplinares, conhecendo estratégias que o levam a ensinar e a aprender, promovendo uma compreensão crítica dos conteúdos com capacidade comunicativa para reconhecer o impacto das novas tecnologias de comunicação e informação. Para que isso seja possível, urge a necessidade de uma formação adequada e de políticas públicas que garantam a participação dos professores e o desenvolvimento de competências necessárias. 
Percebe-se, portanto, nesta pesquisa, a necessidade de mudanças profundas nas estruturas das bases educacionais, de modo a ampliar as possibilidades de expressão, em que cada um pode se colocar de acordo com sua cultura e seu contexto, tendo o YouTube como importante possibilidade da expressão livre de modelo ou padrão pré-estabelecido. Nesse sentido, o professor poderá ser coordenador, orientador, aquele que vai oferecer estímulos e objetos a serem experimentados, proporcionando a aprendizagem.

Durante esta pesquisa, portanto, foi identificado que muitos professores não conheciam possibilidades diversificadas oferecidas pelo YouTube, já que a maioria se limitava a assistir aos vídeos on-line, mas alguns não sabiam como, por exemplo, baixar, copiar os vídeos e levá-los para a sala de aula. Além dessa possibilidade, outras como criar um canal, criar lista dos vídeos favoritos e organizá-los por tema na sua conta YouTube, também eram desconhecidas pelos professores. Diante disso, a oficina "Possibilidades do site de rede social YouTube na Educação", buscou utilizar-se de conteúdos teóricos e práticos para auxiliá-los na ampliação e na melhor utilização dos recursos disponíveis no site de rede social YouTube em suas atividades pedagógicas.

Ao descrever e refletir sobre o percurso da pesquisa, nota-se que apenas uma das professoras participantes da oficina conseguiu utilizar o YouTube para além de pesquisar e obter informações. Durante a oficina realizada, ficou evidenciado que a referida professora possui imersão na cibercultura, já sendo autora de blog e de perfis em redes sociais da internet. Por outro lado, mesmo tendo o domínio do YouTube, a oficina contribuiu para ampliação de seus conhecimentos, possibilitando que ela produzisse e compartilhasse novos vídeos em seu canal no YouTube e, inclusive, colaborasse para que outros professores se sentissem mais à vontade para utilização dessa rede social, numa relação de formar-se e formar ao outro.

Sabe-se, porém, que a realização de oficinas pontuais não é suficiente para preparar os professores que não possuem imersão nas culturas digitais para trabalhar com as TDIC em sala de aula. Para uma ampla e verdadeira inserção das tecnologias na educação, é imprescindível a formação continuada, conforme ressaltou-se anteriormente, uma formação que possa oportunizar ao professor a aquisição de letramento digital. Essa forma de letramento é muito mais do que simplesmente saber usar as funções básicas das tecnologias digitais ou acessar a internet. Estar letrado digitalmente inclui compreender as tecnologias e suas interfaces digitais não como consumidores de informação, mas essencialmente como produtores de saberes, culturas e conhecimentos compartilhados na/em rede. O professor com 
letramento digital entende que interagir na/em rede potencializa a troca de informações e a construção de conhecimentos coletivos e colaborativos.

Diante das constatações desta pesquisa, acredita-se que, para utilizarmos as possibilidades do YouTube e demais interfaces digitais na educação, é importante a garantia de professores fortalecidos e isso significa ter remuneração adequada que lhe possibilite realizar formação continuada sem sacrificar seu tempo de trabalho para seu aperfeiçoamento profissional. Isso pôde ser constatado quando muitos professores não puderam participar da oficina porque trabalham 60 horas semanais para conseguirem remuneração mais condizente com suas necessidades. Além disso, é necessário ter escolas fortalecidas com infraestrutura adequada não apenas em termos de materiais, de espaços físicos, tecnologias digitais e acesso à internet, como também no que se refere ao suporte tecnológico e ao corpo administrativo capaz de entender a necessidade de uma gestão que realmente se preocupe com todos os aspectos da escola, buscando manter as tecnologias sempre funcionando em condições adequadas e acessíveis ao professor da forma menos burocrática possível.

\section{Referências}

ARDOINO, J. Para uma pedagogia socialista. Brasília, DF: Editora Plano, 2003.

JOSSO, M. C. Caminhar para si. Tradução de Albino Pozzer, revisão de Maria Helena Menna Barreto Abrahão. Porto Alegre, RS: EDIPUCRS, 2010.

LUCENA, S.; PRETTO, N. De L. As novas educações e os potenciais da TV e das redes digitais. In: REUNIÃO ANUAL DA ANPED, 32, 2009, Caxambu, MG. Sociedade, Cultura e educação: novas regulações. Anais [...]. Rio de Janeiro, RJ: Anped, 2009. v. 1. p. 1-16.

MACEDO, R. S. Compreender/mediar: o fundante da educação. Brasília, DF: Liber Livro, 2010.

MACEDO, R. S. Outras luzes: um rigor intercrítico para uma etnopesquisa política. In: MACEDO, R. S.; GALEFFI, D.; PIMENTEL A. Um rigor outro: sobre a questão de qualidade na pesquisa qualitativa. Salvador, BA: Edufba, 2009. p. 75-126.

RIBEIRO, M. R. F. A sala de aula no contexto da cibercultura: formação docente e discente em atos de currículo. 207 f. Tese (Doutorado em Educação) - Universidade do Estado do Rio de Janeiro, Rio de Janeiro, 2015.

SANTAELLA, L. Comunicação ubíqua: repercussões na cultura e na educação. São Paulo: Paulus, 2013.

SANTOS, E. O. dos. Pesquisa-Formação na Cibercultura. Rio de Janeiro: Editora Santo Tirso, 2014. 
SANTOS E. O. dos. O que muda na Educação. Entrevista para o programa Salto para o futuro. Série Cibercultura. 2011. Disponível em: https://edumidiascomunidadesurda.files. wordpress.com/2016/05/salto-para-o-futuro-cibercultura-o-que-muda-na-educac3a7c3a3o. pdf. Acesso em: 07 out. 2017.

SILVA, A. de S. Arte e tecnologias móveis hibridizando espaços públicos. In: PARENTE, A. (org.). Tramas da rede: novas dimensões filosóficas, estéticas e políticas da comunicação. Porto Alegre: Sulinas, 2013. p. 282-297.

VELOSO, M. M. de A. O professor e autoria no contexto da cibercultural: Rede de Criação no cotidiano escolar. 300 f. Tese (Doutorado em Educação) - UFBA, Salvador, 2014. 